\title{
Breaking the Stereotype: The Case of Online Gaming
}

\author{
MARK D. GRIFFITHS, PH.D., MARK N.O. DAVIES, PH.D., \\ and DARREN CHAPPELL, B.Sc.
}

\begin{abstract}
Despite the rise of computer games as a leisure phenomenon, there has been relatively little research into this area. Furthermore, almost all of the research to date has concentrated on arcade or console games. More recently, the Internet has become a new medium in which players can play videogames. Since there is no published research in this area, some "benchmark" data on which future research can build was collected from two online gaming fan sites. Sociodemographics showed that the majority of players were male (approximately $85 \%$ ). Over $60 \%$ of players were older than 19 years. The data provide clear evidence that the game clientele is very much an adult profile and suggest a different picture to the stereotypical image of an adolescent online gamer. The stereotype of the typical online player being a socially withdrawn young male with limited sex role identity appears to be misplaced.

\section{INTRODUCTION}

I N THE EARLY 1990s the phenomenon of computer gaming in the home came into its own with the development of dedicated gaming console machines such as Sony's PlayStation, Sega's DreamCast, and Nintendo's Super Nintendo. Out of this new form of entertainment, new celebrities began to emerge. These new 'pixel heroes' such as Sonic the Hedgehog or Super Mario Brothers became household names and even had their own television shows or films made in their name. The culmination of this 'cyber idolatry' is the international fame of Lara Croft from the extremely successful Tomb Raider series. It has even led to Lara Croft as a Film Icon alongside an advertising campaign for a soft drink, where women seek to take on the persona of Lara Croft.

Despite the rise of computer games as a leisure phenomenon, there has been relatively little research into this area. A majority of the

research to date has concentrated on adolescent players.1,2 Furthermore, most of the research has tended to concentrate on the more negative aspects such as excessive play and addiction, ${ }^{3-7}$ the effects of playing aggressive games, ${ }^{8,9}$ and the medical and psychosocial consequences. ${ }^{1,10}$ However, there have been a few psychologically-based studies on personality and computer game play 11,12 although these have been exploratory. Thus, the image of a typical gamer (and the pastime of computer gaming) is seen as socially negative and remains firmly within a youth subculture.

As the 1990s came to a close, a new generation of machines with increasingly sophisticated processing power began to replace the early 1990s consoles. However, an even more revolutionary development was also occurring involving the Internet as a gaming forum. New games emerged that enabled people to link up online to game together. The games varied in their mode of operation. There are
\end{abstract}


basically three main types of social virtual gaming over the Internet-Stand Alone Games, Local and Wide Network (LAWN) Games, and Massively Multiplayer Online Role-playing (MMORP) Games.

\section{STAND ALONE GAMES}

Games placed in this category of 'Stand Alone' are defined as single player orientated games for the PC with the option to go online to seek a human opponent. However, the main use of 'Stand Alone' games, until very recently, has been to pitch player versus computer. Examples include Black $\mathcal{E}$ White, Dungeon Keeper II, and Diablo II. These games, if played online, by definition do not immerse a player into a virtual, narrative-enriched world. Where players can choose to represent themselves as a single character, they are usually fixed in the view offered (e.g., over the shoulder) and rarely do players engage in grouping behavior. Player communication is possible, but the depth of the social immersion in the game is restrained by the lack of a clear game narrative.

\section{LOCAL AND WIDE NETWORK (LAWN) GAMES}

LAWN games arose from the desire to link players together in support of tournaments. Examples of this style of gaming include Quake III and Counterstrike. The main style of play involved in these games is tactical combat. Common to the games is a limited game narrative, with an emphasis on tactical play. Character development is very limited, if existent at all. Out of this style of gaming has arisen gameplay where people group in 'Clans'. For example, in Counterstrike their identity is akin to an army's special operation forces or terrorist group. The Clans then meet in cyberspace to compete in deadly combat. The aim of these Clans is to kill or destroy opponents. The kill is usually denoted by the term Frag and the view is first person. The Clans may also have a real existence (i.e., people living together in the real world) or may be a virtual grouping. This form of gaming has grown in popularity to such an extent that 'LAN parties' are now regularly held where hundreds to thousands individuals meet and link up transported PCs to compete over a weekend. A further development has been professional games' tournaments and emergence of professional gamers.

\section{MASSIVELY MULTIPLAYER ONLINE ROLE-PLAYING GAMES (MMORPG)}

MMORPG are the latest Internet-only gaming experience. These are typically represented by large, sophisticated, detailed and evolving worlds based in different narrative environments. Examples of such games are Everquest (heroic fantasy), Anarchy Online (futurist science fiction), and Motor City Online (classic car racing). In these games the nonplayer characters (NPCs) are designed with advanced artificial intelligence (AI) that offers a rich and unpredictable mileu for players to experience a virtual world through their own 'player character'.

The nature of these games is to offer a rich three-dimensional world that is populated by thousands of players. This game form is a fully developed multiplayer universe with an advanced and detailed world (both visual and auditory). The most popular and therefore largest of these MMORPG is Sony Online Entertainment's EverQuest which reports having over 400,000 people playing it. ${ }^{13}$

To play Everquest, a player has to log on to a Server that hosts the Everquest world. Sony currently supports 44 servers and each server runs a full version of the Everquest world. On each server there are typically around 2,000 players at any one time. Most of these servers (39 out of 44) are based in America, although the five latest servers are based in Europe.

The game allows a range of identities (and genders) to be explored by playing a character created by the player. The identity can vary along the lines of race, profession, and deity alignment (morality). As a result each character can be played as good or evil, a friendly or unfriendly race, and a profession that is seen as a team player or more of a loner. A player's 
choice will impact directly on the game, as NPCs will respond to the character's profile. For example, a 'player character' troll will have low faction (see glossary) with dwarven NPCs and therefore will initially be kill-onsight (KOS). However, the faction can be raised by undertaking deeds, which in the eye of the dwarves, makes the player the exception rather than the rule.

Once in the virtual world, the players can either group or play solo. The social communication is via on-screen text. This can either be done privately (within a group of up to six players) or across the 'zone' that includes all players in the zone. Zones are different areas within the game on the same server. Interzonal communication is possible through Guilds and private text messages. The game developers are currently exploring interserver communication. In addition, due to the visual richness of the games it is possible to 'emote' visually, i.e., signal an emotional state by gesture such as kneeling, saluting, waving, etc. Within these self-contained worlds, a rule-governed behavior emerges from the various interactions between players (within the parameters of reasonable behavior).

Although computer gaming is now seen as very much in the mainstream of cultural pastimes (no longer only part of the youth culture) very little is known about the psychology of online gaming. There is very little data even on the basics. For example, the relationship between personality and amount of time spent gaming (or the type of gaming pursued) has received little attention. What data there are, suggest that gaming in general, particularly online fantasy gaming, is associated with introversion, lower empathic concern, and low feminine identity. ${ }^{11}$ Case study reports concerning the impact of online gaming have shown detrimental effects, although these studies concerned excessive online gaming use rather than occasional or regular use. ${ }^{14}$ With the advent of the new, visually rich, virtual online worlds, an opportunity exists to explore the psychology both of players who engage in this new form of entertainment, as well as the psychology of players within the world itself. Before such research can be un- dertaken, there is a need to establish some "benchmark" data on which future research can build. At present we know nothing about who plays online computer games and how similar or different they are from those who play 'Stand Alone' computer games or engage in $L A N$ tournaments. In an attempt to establish some benchmark data, this study collated data from two online gaming fan sites. Both sites support Everquest. As there is no empirical data relating to online gaming, this was a purely exploratory study with no hypotheses.

\section{METHOD}

Data were collected for secondary analysis at two fan sites for Everquest players. The two sites chosen for analysis were Everlore (www. everlore.com) and Allakhazam (everquest. allakhazam.com). These two Internet resources are the leading sites that support Everquest players. Each of these sites conducts a regular poll (on average) every 2 to 4 weeks. Only one question is asked in the poll and can be about anything that may be of potential interest to other Everquest players. Polls have been running at Everlore since June 1999 and at Allakhazam since July 1999. Everquest came online in February 1999.

The authors examined every poll question and data set on both fan sites from their inception up until June 2002. The first aim was to collate all data relating to sociodemographic variables in an attempt to assemble player profiles (e.g., age, gender, nationality, educational attainment, financial income). Other data relating to various aspects of online game playing were also examined, including the frequency of play, length of time as a player, favorite and least favorite aspects to the game, and the prevalence of particular game playing behaviors (e.g., gender swapping, role playing). As the authors had not set any of the poll questions, the data were necessarily limited to the poll questions set by the fan site hosts. It must also be pointed out that all of the individual data sets consist of self-selected samples. However, as can be seen from Table 1, all of the sample sizes are large and there is nothing to 
Table 1. Summary of Sample Size for Poll Questions/Date of Question Set

\begin{tabular}{lll}
\hline Variable & \multicolumn{1}{c}{$\begin{array}{c}\text { Everlore } \\
\text { Sample size/question date }\end{array}$} & $\begin{array}{c}\text { Allakhazam } \\
\text { Sample size/question date }\end{array}$ \\
\hline $\begin{array}{l}\text { Sociodemographic } \\
\text { Age }\end{array}$ & 11,457 (May 1999) & 12,538 (May 2000) \\
Gender & 9.618 (May 1999) & 8,694 (Jan 2000) \\
Nationality & - & $15,788($ Feb 2001) \\
Education level & - & 7228 (Jan 2001) \\
Financial income & 9,022 (Jun 1999) & - \\
Gaming & - & $8,882($ Apr 2000) \\
Play frequency & 2,536 (June 2001) & - \\
Playing history & 13,568 (Nov 1999) & - \\
Main playing activity & 10,350 (Dec 1999) & 8,694 (Jan 2000) \\
Gender swapping & 2,145 (July 2001) & - \\
Role playing & - & 11,290 (Oct 2000) \\
Favorite aspect & - & 18,045 (Nov 2000) \\
Least favorite aspect & 5,735 (Apr 1999) & - \\
Player vs. player & - & 3,495 (Jun 2000) \\
Grouping with others & - & 7,383 (Dec 1999) \\
Number of characters & 10,090 (Oct 1999) & - \\
Level of character & - & 12,375 (Oct 1999) \\
Typical player & &
\end{tabular}

suggest that these samples are not representative of online game players.

\section{RESULTS}

Sociodemographic characteristics

of online game players

Age and gender. Of the 11,457 players on the Everlore fan site who responded to the question of how old they were, the vast majority of the sample was aged between 14 and 29 years (72\%). Of the remaining $28 \%$ of players, only $9 \%$ were under the age of 14 , and $6 \%$ over the age of 40 years. A full breakdown can be found in Table 2. On a different fan site, similar results were found, although the age breakdowns were slightly different. Of the 12,538 players who responded on the Allakhazam fan site, the majority of the sample were aged between 10 and 30 years (71\%). Of the remaining $29 \%$, only $1 \%$ were under the age of 10 years, and only $8 \%$ over the age of 40 years. A full breakdown is also given in Table 2. Of the 9,618 players on the Everlore Fan site who responded to the question about their gender, the majority of the gamers were male $(84 \%)$. This figure was very similar to a sample of 8,694 players at the Allakhazam fan site where $86 \%$ of players were male.

Nationality. In a question about nationality, the vast majority of the 15,788 players on the Allakhazam fan site were North American (73\% American and 8\% Canadian). The remaining sample consisted of those from the UK $(4 \%)$, Germany (2\%), Australia (2\%), Sweden (2\%), France $(2 \%)$, and numerous countries that ac-

Table 2. Age Summary of Online Gamers by Percentage

\begin{tabular}{lcclllllll}
\hline \multicolumn{7}{c}{ Sample 1 (Everlore Fan Site) } \\
\hline Age (years) & $<14$ & $14-18$ & $19-23$ & $24-29$ & $30-39$ & $40-59$ & $>60$ & \\
Percent & 9 & 31 & 21 & 20 & 13 & 3 & 3 & $(\mathrm{n}=11,457)$ \\
\hline \multicolumn{7}{c}{ Sample 2 (Allakhazam Fan Site) } \\
\hline Age (years) & $<10$ & $10-20$ & $21-30$ & $31-40$ & $41-50$ & $51-60$ & $>60$ & \\
Percent & 1 & 25 & 46 & 20 & 5 & 2 & 1 & $(\mathrm{n}=12,538)$ \\
\hline
\end{tabular}


counted for the remaining $7 \%$ of the total sample (e.g., Denmark, Taiwan, Austria, New Zealand, Japan, and Switzerland).

Education level. In a question about educational level, players on the Allakhazam fan site had a wide variety of education. Thirty-three percent of the sample were still at an educational establishment, including those currently in middle school (3\%), high school $(14 \%)$, college $(14 \%)$, and graduate school (2\%). Of those who were in employment, $23 \%$ had a high school diploma, 33\% had an undergraduate diploma, $7 \%$ had a Masters degree, and 2\% had a doctoral degree. A small percentage was retired and did not indicate their educational attainment (2\%).

Financial income. In a question about how much money players on the Everlore fan site earned a year (US dollars), 45\% said they were still studying (30\% in high school and $15 \%$ in college). The remaining 55\% were divided between those that earned less than $\$ 35,000$ a year $(21 \%)$, those that earned between $\$ 35,000$ and $\$ 60,000(20 \%)$, and those that earned over $\$ 60,000$ a year $(14 \%)$.

\section{Characteristics of online game playing}

Frequency of play. In a question about how many hours a week they participated in online gaming, there were wide variations in the sample of 8,882 players on the Allakhazam fan site. A small percentage ( $8 \%$ ) played for less than 10 hours a week, a quarter $(25 \%)$ played between 10 and 20 hours a week, a quarter (25\%) played between 21 to 30 hours a week, and $18 \%$ played between 31 and 40 hours a week. Of the remaining $24 \%$ of players, $9 \%$ played between 41 and 50 hours a week, with $15 \%$ playing over 50 hours a week.

Playing history. In a question about how long they had been gaming online, there were a wide range of responses although no one had been playing for much more than 2 years. Responses from the 2,536 players at the Everlore fan site ranged from those who had just started (3\%), 1 to 2 months (8\%), 4 months $(12 \%), 8$ months $(19 \%)$, a year $(19 \%)$, a year and a half $(11 \%)$, around 2 years $(14 \%)$, and over 2 years $(13 \%)$.

Main playing activity. Players at the Everlore fan site were asked what they do most when gaming online. Of the 13,568 players who responded there was a wide range of responses. In order of what they do the most in the game, the players reported soloing $(31 \%)$, grouping $(19 \%)$, dying $(14 \%)$, exploring $(9 \%)$, socializing $(8 \%)$, trade skills $(5 \%)$, camping $(5 \%)$, quests $(4 \%)$, complaining $(2 \%)$, and $3 \%$ other activities.

Role-playing. Players at the Everlore fan site were asked if they actually role-play when gaming online. Of the 2,145 players who responded, $24 \%$ always role-played, $47 \%$ roleplayed on some occasions, and $29 \%$ never role-played at all.

Favorite aspect of playing. Players at the Allakhazam fan site were asked what their favorite aspect of playing Everquest was. The responses of the 11,290 players who responded to this question reported: leveling and building up their character (26\%), grouping and interacting with other people $(23 \%)$, exploring new places $(15 \%)$, chatting with friends and guild mates $(10 \%)$, finding new items and equipment $(8 \%)$, role playing $(5 \%)$, solving quests $(3 \%)$, creating items through the trade skills $(2 \%)$, dueling and player killing (2\%), buying and selling items in the game $(2 \%)$, and killing a variety of mobs (2\%). There were many other idiosyncratic favorite aspects that accounted for the final $2 \%$ of responses.

Least favorite aspect of playing. Players at the Allakhazam fan site were asked what their least favorite aspect of playing Everquest was. The responses of the 18,045 players who responded to this question reported : the difficulty of advancing for casual players (14\%), the death penalty experience loss (13\%), camping $(11 \%)$, the difficulty of playing solo $(11 \%)$, overcrowding (9\%), inability for noncasters to bind $(8 \%)$, the downtime between fights $(7 \%)$, imbalance/nerfing of the classes $(6 \%)$, the verant customer service (5\%), the long traveling times $(4 \%)$, the ability to twink characters $(4 \%)$, and the game's bugs (3\%). In addition to 
this, there were many idiosyncratic reasons given as the least favorite aspect $(3 \%)$, and a further $2 \%$ who claimed they loved every aspect of the game and did not have a least favorite aspect.

Grouping with other people. Players at the Allakhazam fan site were asked who they usually group with when playing. Of the 3,495 players who responded, the results were whoever was available when they shouted for a group (34\%), friends they had met while playing the game $(24 \%)$, guild mates $(16 \%)$, real life friends and family (14\%), or nobody because they were solo players (12\%).

Gender swapping. Players at the Everlore fan site were asked if they are the same gender as their online gaming character. The vast majority of the 10,350 players said that they were $(85 \%)$, although a significant minority did gender swap $(15 \%)$. Players at the Allakhazam fan site $(N=8,694)$ were also asked about the gender of their main character. Results showed that $15.5 \%$ of the sample gender swapped $(14.5 \%$ of the sample were males who were female as their lead character, and $1 \%$ were females who were male in their lead character).

Number and level of characters. Players at the Allakhazam fan site were asked how many characters they regularly played with while gaming online. Of the 7,383 players who responded, $28 \%$ played with just one, $37 \%$ played with two, $21 \%$ played with three, $7 \%$ played with four, and the remaining $7 \%$ played with five or more. Players $(N=10,090)$ at the Everlore fan site were also asked what level their main character was. In ascending order, their responses were: levels 0-10 (20\%), levels $11-20(38 \%)$, levels $21-30(22 \%)$, levels $31-40(11 \%)$, levels $41-45(6 \%)$, and levels 46-50 (3\%).

Typical player. Players at the Allakhazam fan site were asked (typically speaking) what type of player were they while gaming online. Of the 12,375 players who responded, the results (in order) indicated they were explorers (34\%), role players $(22 \%)$, power levelers $(23 \%)$, chat/socializers (14\%), newbies (5\%), and kill stealers $(2 \%)$.

\section{DISCUSSION}

This is the very first time that data relating to online gaming have been collated and presented in this form. They are therefore of great existential value as future research in the area can be measured against these benchmark secondary data. The data relating to sociodemographic characteristics of online game players revealed some interesting results. Although (as expected), both sites showed that the majority of players were male (approximately $85 \%$ ), there were clearly a significant number of female players too (approximately 15\%). The data for age and gender from the Everlore site was from 1999 while the Allakhazam site data was from 2000. Therefore it is not unreasonable to suppose that they are not the same sample and there is remarkable consistency in the data pattern. It is also worth noting that the Everlore data has $60 \%$ of players older than 19 years and the Allakhazam data had nearly three-quarters of players (74\%) over 21 years.

The data provide clear evidence that the game clientele is very much an adult profile and suggest a different picture to the stereotypical image of an online gamer. The stereotype of the typical online player being a socially withdrawn young male with limited sex role identity appears to be misplaced. For instance, there is significant minority of women that play MMORPG. Additionally, it is very striking to find people over the age of 40 years take part. One of the most consistent points coming out of the polls is the significance of the social milieu in determining the enjoyment from play.

The game is clearly spread across the age (and to some extent gender) spectrum and is not limited to adolescents. The breakdown of educational achievement also indicated that the sample were generally well educated with approximately $50 \%$ having an undergraduate degree. Further to this, there are those who were still studying and they themselves might end up with at least an undergraduate degree. With regards to financial income, it is difficult 
to evaluate without any normative data for the US at the time of the poll. It appears that the income and education level is higher than the average population but we cannot confirm this.

With regards to nationality, it was unsurprising that North Americans dominated as they have traditionally been host to all the servers. The data for this question was collected in February 2001 and was prior to any European servers. Since the data were collected, Sony has introduced two European servers. This is crucial as most gamers (although not all) are European on these servers and therefore play the game in the same (or very similar) time zones. If this question were repeated now, we would expect to see an increase in the number of Europeans.

Questions relating to the characteristics of online game playing also yielded interesting results. The frequency of play clearly covers the behavioral continuum, with some players participating for relatively small amounts of time, whereas others appear to be doing almost nothing else but playing the game. The most striking finding was that a quarter of the sample played for more than 41 hours a week. This is evidently a significant amount of leisure time and almost certainly impacts on other activities and commitments. Some of these people (particularly the 15\% who claim they play the game over 50 hours a week) may in fact be addicted to playing the game. Even if they are not "addicted" to the game, any activity taking up this much time in someone's life would be having a compromising effect somewhere in their life (whether it be their relationship, their job/schoolwork, or other hobbies / pastimes). Future research is needed on these heavy players to examine what effect excessive play is having on all areas of their life. It would be useful in future research for addiction screening instruments to be given to this excessive playing population, as has been done in other studies of offline computer game playing. 4,6

With regards to the playing history, it was evident that most players were fairly new to the Everquest game, with $61 \%$ claiming they had played it for a year or less. The data itself was collected approximately two and a half years after the start of Everquest and therefore the data appear fairly reliable.

In relation to the main form of online playing activity, the data clearly indicate that the main activity 6 months after the start of the game was solo play (31\%). This is akin to stand-alone gaming, but just over a quarter of players $(26 \%)$ do have human interaction as a prime focus. Role-playing is also important. Data indicated that nearly three quarters of players $(72 \%)$ role-play at some point. Given there is no material game incentive to roleplay this is quite striking. To role-play, the player has to interact with other players. This would also suggest that game play is not simple. For example, although someone may like to play solo in the game, they will also group and / or role-play. This demonstrates the attraction of the social element in online game playing. This ties in with the data collected relating to players favorite aspects of Everquest. Data reveal that $41 \%$ of the favorite aspects of the game concern social interaction (i.e., group interaction $[26 \%]$, chatting $[10 \%]$, and roleplaying [5\%]). It is also interesting that the 'antisocial' violent option of killing other players (or even mobs) only makes a combined total of $4 \%$. This counters the argument that computer gaming promotes and encourages violent behavior (see Griffiths ${ }^{8}$ for an overview). However, it could be that the online gaming is a completely different experience to offline gaming and that the arguments surrounding the role of aggression have little crossover in the online version.

The data specifically on grouping with people was interesting. The data suggests that three distinct 'types' of player can be identified-those who group to play (34\%), those who play to group (55\%), and those who do not group $(12 \%)$. The classification is almost certainly not as straightforward but are useful tags for the building of further research.

The least favored aspects of the game predominantly focused on either game mechanics or customer service (accounting for $82 \%$ of responses). The remaining two elements could be loosely interpreted as issues to do with social processes. The difficulty in soloing (11\% of players) is simply because the player has no one to rely on as back up when the fight gets 
tricky. The problem of' 'downtime' between fights could be interpreted as an issue of players not wanting to spend time chatting and engaging in social exchange that does not have a specific game benefit. However, this is still a low percentage of players $(7 \%)$.

Some of the most interesting data of the whole study concerned the act of gender swapping. A significant minority clearly admitted to gender swapping (15\%). Furthermore, a higher percentage of males $(17 \%)$ engaged in gender swapping when compared to females $(10 \%)$. This gender difference is interesting and requires further research. It could be that female players are more comfortable with their gender image or that male players are more adventurous in their gender roles. Male players may be stimulated more by seeing a visual representation of themselves as female, in contrast to female players represented as male characters. It could also be argued that MMORPG favor 'male' behavior, i.e., resource accrual, aggression, and risk-taking. However this assumes that such a dichotomy exists. Alternatively, females may be less attracted to a male persona (e.g., violent criminal behavior). In contrast, the female persona has a number of positive attributes, especially socially in a male-orientated environment, and this may help to explain why gender swapping is more male-to-female. For example, female characters often receive comments on their beauty during role-play and may well receive greater help and support during interactions.

Data relating to the number of characters and levels played was less than might have been expected. Two-thirds of players (65\%) had only one or two characters. However, all of the data for these two questions were collected in 1999. This may well explain the low number of characters. It may also reflect the desire to concentrate on depth rather than breadth. The maximum number of characters that can be played on a server is eight. As for level, the ceiling in 1999 was 50. In the current game, the level maximum is 60 . Well over half of players $(58 \%)$ had characters level 20 or below. At level 20 a player can consolidate their character by being invited to choose a surname. This is a significant event in the identity of the character. Fifty-eight percent is a high number in relation to the main character. However, this is likely to be in relation to the date of the poll and the fact that the game was new at the time. Over time, it is probable that a player tries to attain the highest level for their character. Consequently as world knowledge grows, the player is encouraged to explore other facets of the game through additional characters.

Players were asked (typically speaking) what type of player were they while gaming online. Over one-third were explorers (34\%), with both role players (22\%), and power levelers $(23 \%)$ accounting for over a fifth of the players. There were also other lesser types (chat/socializers, newbies, and kill stealers). The explorers are clearly open to new experiences and that is what players experience when exploring in Everquest (e.g., meeting new characters). Power levelers play the game mechanics. An abuse of game mechanics is seen in kill stealing. It is so much frowned upon that sanctions can be imposed on the player if they continue to kill steal by those running Everquest. Over a third (36\%) are socially focused (i.e., role players and socializers). Those more used to single player console games would probably account for the Power Levelers. Again, the data for this question was an early poll. It is more likely that this is much lower as players eventually realize with experience that the grouping and helping of other players is the more fun (and necessary) style of play.

It is interesting to note that on the few occasions that both fan sites featured the same questions, the concordance between the results was incredibly high. For instance, the questions relating to age, gender, and gender swapping showed almost identical results. This suggests that the self-selected samples are representative of online game players. Alternatively, it could perhaps be argued that the same players are filling out both sets of poll questions at each of the sites! Although technically possible, it is unlikely that the sample is the same one. The polls were not concurrent with each other. This adds validity to the data.

Studies in this area may eventually reveal differences (psychological or otherwise) between online computer game playing and tra- 
ditional computer game playing. Although there are clear overlaps between the two genres of playing, games such as Everquest are always evolving and changing (unlike traditional console games). For example, long-time players will often discover new mobs, quests, items, etc. in zones that they know very well. Console games are sophisticated, involving, and often challenging. However, rarely do they evolve worlds-they have rather fixed narratives that a player has to navigate through. As with console games, when a person reads a book or watches a film, it is essentially a solitary experience. In contrast, participating in MMORPG is only really matched by other role-playing games, participation drama, and other similar activities.

There are also differences in terms of roleplaying (i.e., not everyone likes role-playing style games). As more and more MMOG (massively multiplayer online games) come out with different genres, the single player game will start to diminish. At present with Everquest, these are different types of people that would say play a 'shoot 'em up' or 'beat 'em up' type game. Everquest is not an easy game to play for an hour, and so it takes an intelligence and perserverence to work things out. The main attraction to Everquest (and all other MMORPGs) is the social interaction with other players. If the Everquest world consisted solely of nonplayer characters, the number of active players would simply diminish. Players have made friendships with other players outside of the game.

There are a number of limitations to the present study. This study was carried out on one particular online game (Everquest). Some may question whether the findings reported here have any validity to other types of online computer games. Obviously the kind of research outlined here needs to be at least replicated with other games (such as Asheron's Call). Other online games may attract different types of sociodemographic clientele. For instance, Asheron's Call is seen by the Everquest community as easier and less demanding, so is likely to appeal to the younger gamer. However, generalizability may not be the key issue here. The issue is not how they can be transferred to other online games, but what basic principles of behavior can we identify that represents the new contemporary Internet gamer. Although we have to be cautious about our interpretation, we can make some confident predictions given how other games are organized. For example, the chat facility is common in MMORPG, LAWN, and Stand Alone games. The difference in MMORPG is what the chat is used for.

Secondly, the study used self-selected samples from secondary data sources. There is therefore an issue about representativeness. However, the self-selecting sample came from a highly motivated (and by definition Internet literate) population. Furthermore, the lack of primary data is not problematic as the two polls offered similar (although not exactly the same) data. Another limitation was that each poll question was independent of each other (therefore no cross-referencing of the data was possible). It may be that given the large numbers of respondents, that many of the same people participate in all of the polls and across fan sites. However, Everquest population numbers hundreds of thousands and the Allakhazam site has nearly 200,000 registered users alone.

Some of the questions are very old in gaming terms (e.g., 3 years in some cases). Demographic variables may have changed even in such a relatively short space of time (e.g., there may have been an increase in number of females playing). Everquest has been running since February 1999. Therefore polls held in 1999 are very likely not to be representative of the current demographic. This is important, as the data from 1999 was already not supportive of the stereotype (e.g., gender).

The data indicate a clear difference between players of Everquest (which is a massively multiplayer online game) compared to that of single player games. First, the age range of Everquest players is generally spread between the twenties and thirties. The lack of young adolescents could be the result of having to own a credit card to actually play the game. Nevertheless, these data would indicate that the computer gaming world is no longer directly aimed at the younger audience. There are also significant numbers of female players. Everquest play is also concerned with grouping 
and helping others. This may be a 'pull' factor for the small but significant female audience. Male players tend to be more concerned with 'power leveling' and success (in character building and levels).

Everquest, Asheron's Call, and Ultima Online are just a few of the MMORPG that are available. However, with more sophisticated and advanced technology, and with increased Internet speeds, MMORPG will become a very popular gaming format. Games in production include Star Wars Galaxies. Verant Interactive (maker of Everquest), has teamed up with Lucas Arts to create a massively multiplayer, online RPG in the Star Wars universe. In this game, players can take part in battles, dedicated missions, and heroic quests. This game is more likely to appeal to a larger audience than (say) middle earth quasi-medieval games such as Everquest or Asheron's Call. The Matrix Online is another massively multiplayer game, though the emphasis will be on fighting instead of character building. A very successful film may produce a very successful game. 2003 will also bring Everquest 2: The Age of Density, the much-awaited sequel to the successful predecessor Everquest. More human added habits have been added such as property buying or at least land occupancy.

There is clearly much research needed in this area of the gaming world, as there is little research even on the most basic aspects of online gaming. Even with secondary data presented here, there is evidence that some people play excessively, and (that in some cases), addiction may exist. This may also prove a productive area for further research.

\section{APPENDIX: GLOSSARY OF TERMS}

Bind-Your bind point is the place in the game where your character will resurrect once you have died. Some characters have the power to change their binding spots.

Camping-There are three possible uses of the term in the game. 1. (v) Usually camping means that the player wishes to exit the game and must camp to do so. 2. (v) A player or players wish to wait near an NPC's known bind point in an attempt to kill it repeatedly for experience and rare items. 3. (v) In playerversus-player games Camping also refers to hiding in a difficult-to-reach location in order to pick off other players by way of ranged weapons or spells.

Clans-An organized gaming team which enters leagues and tournaments.

Emote-To express a physical emotion using the keyboard. For example, in Everquest,

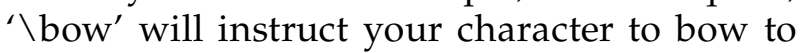
another player. Other emotions include kneeling, waving, and saluting.

Faction-In the most basic form, faction is simply street creditability or worthiness in the eyes of NPCs. It is inevitable that there will be enemies amongst the races. When players make friends with one particular race, this can consequently make you disliked or hated by another, so as your faction goes up with one race it will go down with another. This effect is not an all or nothing, but is a gradual process.

Frag-To frag someone means to kill them. For each kill you are awarded 1 frag (point). Hence, it is a scoring tool in tournament games.

Guilds-A guild is a collection of players who share a common principle or outlook. A guild is a specialized group. Guilds are popular among the variety of MMORPG available. Often guilds will have a deity alignment (good, evil, neutral) and carry out actions consistent with that alignment. However any players that are caught behaving badly or against the policies of the guild will be dealt with appropriately, such as being expelled from the guild.

LAN-(Local Area Network). A LAN is a type of network topology that is commonly used in businesses and organizations. It is a means of networking computers within an internal specified area.

MOB-The NPCs that constitute the adversaries in the game. Therefore a mob can be single NPC or a large number of monsters. 
Nerfing-Changes to game mechanics that are perceived as detrimental from the player's perspective. For example, changes to a spell or weapon effect so that it is effective at causing damage to an opponent.

Newbie-A newbie is a character/player who is starting out. Therefore for all new characters there are 'newbie' zones where it is relatively safe to adventure.

NPC - This is a character in a game that is controlled by artificial intelligence or a Gamemaster (human controllable characters often employed for guidance and help within the game, i.e., customer services).

Server-A powerful machine that hosts various software, files, and information to computers that connect to it. Game servers will hold the gaming worlds data, all details of characters/players connected to it that will provide feedback to all the computers (clients) around the world.

Zone-A zone can encompass an expansive desert or be a city. Zoning usually implies a small delay or pause to the game as additional data from the server is needed to update your characters geographic point and to load up the new area of play.

\section{REFERENCES}

1. Griffiths, M.D. (1996). Computer game playing in children and adolescents: A review of the literature. In: Gill, T., (ed.), Electronic Children: How Children Are Responding To The Information Revolution. London: National Children's Bureau, pp. 41-58.

2. Griffiths, M.D. (1997). Video games and children's behaviour. In Charlton, T. \& David, K. (eds.), Elusive Links: Television, Video Games, Cinema and Children's Behaviour. Gloucester: GCED/Park Publishers, pp. 66-93.
3. Griffiths, M.D. (1991). Amusement machine playing in childhood and adolescence: A comparative analysis of video games and fruit machines. Journal of Adolescence, 14:53-73.

4. Griffiths, M.D. (1997). Computer game playing in early adolescence. Youth and Society 29:223-237.

5. Griffiths, M.D., \& Hunt, N. (1995). Computer game playing in adolescence: Prevalence and demographic indicators. Journal of Community and Applied Social Psychology 5:189-193.

6. Griffiths, M.D., \& Hunt, N. (1998). Computer game "addiction" in adolescence? A brief report. Psychological Reports 82:475-480.

7. Phillips, C.A., Rolls, S., Rouse, A., et al. (1995). Home video game playing in schoolchildren: A study of incidence and pattern of play. Journal of Adolescence 18:687-691.

8. Griffiths, M.D. (1998). Violent video games and aggression: A review of the literature. Aggression and Violent Behavior 4:203-212.

9. Griffiths, M.D. (2000). Video game violence and aggression: Comments on 'Video game playing and its relations with aggressive and prosocial behaviour' by O. Weigman and E.G.M. van Schie. British Journal of Social Psychology 39:147-149.

10. Griffiths, M.D. (1993). Are computer games bad for children? The Psychologist: Bulletin of the British Psychological Society 6:401-407.

11. Douse, N.A., \& McManus, I.C. (1993). The personality of fantasy game players. British Journal of Psychology 84:505-509.

12. Griffiths, M.D., \& Dancaster, I. (1995). The effect of Type A personality on physiological arousal while playing computer games. Addictive Behaviors 20: 543548.

13. Sony online (2002). Official webpage http:// everquest.station.sony.com/.

14. Griffiths, M.D. (2001). Excessive internet use: Implications for education Education and Health 19:23-29.

Address reprint requests to: Professor Mark Griffiths Psychology Division

Nottingham Trent University

Burton Street

Nottingham, NG1 4BU

United Kingdom

E-mail: mark.griffiths@ntu.ac.uk 